\title{
Chloroquine as a Potential Treatment and Prevention Measure for the 2019 Novel
}

\section{Coronavirus: A Review}

John E. Kearney, B.S., [Corresponding Author] Department of Family Medicine, University of Washington School of Medicine, Seattle, WA 98195

Correspondence: kearneje@uw.edu

Phone: (253) 632-1997

\begin{abstract}
There is a long trail of research studies testing the in vitro and in vivo efficacy of chloroquine and its derivatives in treating and preventing infection by various coronavirus species. More recent findings have highlighted the possibility of treating patients infected with the 2019 novel coronavirus, SARS-CoV-2. This review describes the mechanism of coronavirus infection, the mechanism of action of chloroquine, and summarizes the available literature highlighting the efficacy of chloroquine as an anti-coronavirus agent. These findings should encourage the wider scientific community to conduct thorough research on the possible efficacy of chloroquine and its derivatives in treating and preventing SARS-CoV-2 infection.
\end{abstract}

\section{KEYWORDS}

Antimalarial; Chemoprophylaxis; Chloroquine; Coronavirus; COVID-19; Global Health; Hydroxychloroquine; Public Health; SARS-CoV-2; Virus 


\section{INTRODUCTION}

In December of 2019, a novel human coronavirus outbreak started in Wuhan, Hubei Province, China and then subsequently spread to dozens of other countries becoming a global pandemic. ${ }^{1}$ Severe-acute respiratory syndrome coronavirus 2 (SARS-CoV-2) was found to be the viral agent responsible for COVID-19 pneumonia, the resulting illness from infection. As of this writing, there are 169,387 cases and 6,513 deaths globally, ${ }^{2}$ although the actual rates maybe higher considering low testing and case identification in some regions. The elderly and those who have underlying comorbidities have been disproportionately been afflicted. ${ }^{3,4}$ This outbreak has additionally seen a high morbidity among healthcare workers, ${ }^{2}$ much like previous outbreaks of human coronavirus. ${ }^{6-8}$ The high morbidity among healthcare workers is likely due to both the close contact with infected individuals in a hospital setting as well as evidence of subclinical transmission of the disease. ${ }^{9}$ Alarmingly, despite best efforts to protect healthcare workers, there have also been several deaths among health providers fighting the epidemic. ${ }^{5}$ The burden of disease placed on healthcare workers is problematic for a multitude of reasons including the costs associated with caring for and quarantining infected individuals, the spread of disease in a clinical setting to vulnerable patients, and the strain it places on response efforts due to incapacitated healthcare workers. Preventive measures and effective therapeutics to protect healthcare workers and those who are at risk are vital to combat an infectious disease epidemic. Presently, there are no commonly agreed on prophylactic or therapeutic treatment options for SARS-CoV-2 and a vaccine is not expected to be developed and disbursed to the wider population for $12-18$ months. ${ }^{10}$ However, there are a number of clinical trials ongoing to study the efficacy of older drugs to be repurposed for use against SARS-CoV-2. One such medication includes the antimalarial chloroquine (CQ), which was recently cited as a potential treatment to 
shorten SARS-CoV-2 disease course, mitigate inflammatory responses to infection, inhibit the exacerbation of pneumonia, improve lung imaging findings, and promote a virus negative conversion. ${ }^{3,11,12}$ A number of clinical trials are currently underway as listed on the Chinese Clinical Trial Register to study the efficacy of CQ and its derivatives to treat SARS-CoV-2 (ChiCTR2000029939, ChiCTR2000029935, ChiCTR2000029899, ChiCTR2000029898, ChiCTR2000029868, ChiCTR2000029837, ChiCTR2000029826, ChiCTR2000029803, ChiCTR2000029762, ChiCTR2000029761, ChiCTR2000029760, ChiCTR2000029741, ChiCTR2000029740, ChiCTR2000029609, ChiCTR2000029559, ChiCTR2000029542). ${ }^{13}$ It is worth noting that CQ is recommended to be included in the next version of the Guidelines for the Prevention, Diagnosis, and Treatment of Pneumonia Caused by COVID-19 issued by the National Health Commission of China. ${ }^{11,14}$ On February 19, 2020, the National Health Committee of the People's Republic of China issued the "Diagnosis and Treatment of New Coronavirus Pneumonia (Trial Version 6)," which included the addition of chloroquinephosphate as an antiviral treatment. ${ }^{15}$ Multinational and Chinese drug-makers soon thereafter sped up the manufacturing and supply of chloroquine phosphate and the pharmaceutical company Bayer has expedited the supply and transportation of Resochin (chloroquine phosphate) to Guangdong provincial government at the heart of the outbreak. ${ }^{16}$ Furthermore, in South Korea, the Korea Biomedical Review has also included the use of of the CQ derivative hydroxychloroquine (as CQ is not available in the country) for the treatment of those infected with SARS-CoV-2. ${ }^{17}$

Given the time-consuming nature of developing, testing, and producing new therapeutics, the repurposing of existing pharmaceuticals offers a pragmatic alternative in responding quickly and efficiently to novel diseases. With CQ in particular, there is ample experience in using this drug 
in clinical and population-level settings, its required dosing in humans, its safety and absorption, distribution, metabolism, and excretion. What follows is a review of the mechanisms of coronavirus infection as well as the mechanism of CQ that serve as evidence of its possible efficacy. In addition, this review explores the available literature on the efficacy of CQ and its derivatives for various coronavirus infections in vitro and in vivo. References used in this review were identified through a search of PubMed with the terms "Chloroquine" and "Coronavirus." Articles resulting from this search and relevant references were reviewed and included here. Only articles published in English were reviewed. This review aims to highlight the possible efficacy of CQ as a possible agent to both prevent infection in healthcare providers and vulnerable populations, as well as to treat those infected with the virus.

\section{Mechanism of Action of Coronavirus Infection}

Coronaviruses (CoVs) are enveloped, plus-strand RNA viruses belonging to the family Coronaviridae in the order Nidovirales. ${ }^{18}$ SARS-CoV-2 has many common features with the coronavirus family ${ }^{3}$ and has a phylogenetic similarity to the previous species of SARS-CoV-1 from the outbreak from 2002-2003. ${ }^{19}$ More recent studies found SARS-CoV-2 mimicked SARSCoV-1 in its severity. ${ }^{3,20,21}$ Coronavirus populations exhibit considerable genetic heterogeneity, ${ }^{22}$ however there are common underlying mechanisms.

Coronavirus delivery of virus particles into the host cell requires binding of the virus to cellular receptors followed by a clathrin-mediated endocytosis to create a viral endosome. ${ }^{18,22,23}$ This process is mediated by a viral surface glycoprotein termed Spike, a homotrimer of S proteins, ${ }^{24}$ binding to the type I integral membrane receptor angiotensin-converting enzyme-2 (ACE2), ${ }^{25}$ followed by a $\mathrm{pH}-\mathrm{independent} \mathrm{endocytotic} \mathrm{reaction.} \mathrm{It} \mathrm{is} \mathrm{worth} \mathrm{noting} \mathrm{that} \mathrm{ACE2} \mathrm{is} \mathrm{expressed} \mathrm{at}$ 
high levels in type I and II alveolar cells in the lungs. ${ }^{26,27}$ Once internalized, only then does the fusion of virus with lysosomes depend on a low endosomal and lysosomal $\mathrm{pH}^{28}$ The Sglycoprotein is cleaved into S1 and S2 subunits by endosomal proteases cathepsin B and L, with the resulting S2 subunit mediating membrane fusion. ${ }^{29}$ Cathepsin B and L activity are inhibited by an elevated endosomal $\mathrm{pH}$. Viral entry into the cytoplasm is likewise dependent on an acidic endosomal $\mathrm{pH} .{ }^{30}$ Once released into the cytosol, the virus utilizes a viral RNA-dependent RNApolymerase (i.e. Replicase) to drive the viral replication, ${ }^{31}$ create virions for exocytosis, and thus further the infection of neighboring cells. Previous studies on Human Coronavirus (HCoVHKU1) indicate that infection of alveolar cells is associated with the surface expression of viral Spike protein, mediating membrane fusion with neighboring cells leading to syncytium formation. ${ }^{32}$ This allows direct cell to cell spread of virus which could play a role in the pathogenesis of lung disease and immune system evasion. However, these mechanisms may proceed differently in the novel SARS-CoV-2 as pathogenesis has been shown to differ between coronaviruses. ${ }^{33-36}$

Common symptoms of COVID-19 illness include fever, cough, fatigue, muscle pain, dyspnea (i.e. shortness of breath), expectoration, headaches, hemoptysis (blood in the saliva), and diarrhea. ${ }^{20}$ Laboratory tests revealed elevated levels of liver enzymes, depleted white blood cell counts, and elevated heart enzymes indicating cardiac impairment. The majority of patients given chest computerized tomography (CT) scans were found to have bilateral ground glass-like opacities and subsegmental areas of consolidation ${ }^{20}$ indicative of COVID-19 induced pneumonia. ${ }^{37}$ Severe forms of disease are associated with progression to Acute Respiratory Distress Syndrome (ARDS) ${ }^{38}$ and septic shock. ${ }^{24}$ In some patients, immune response to the virus resulted in an increase in inflammatory cytokines,${ }^{20,39}$ which may progress to a "cytokine storm," 
followed by multi-organ system dysfunction. For severe cases of disease, more invasive lifesaving measures are indicated including admission to the ICU, mechanical ventilation, and extracorporeal membrane oxygenation (ECMO). ${ }^{40}$ There is a higher preponderance of severe disease in patients of older age and who have underlying co-morbidities such as cardiovascular disease, diabetes, chronic respiratory disease, and oncological diseases. ${ }^{24,40}$ Despite life-saving measures, the case fatality rate (CFR) is calculated to be anywhere between $0.5 \%$ and $5 \cdot 0 \%, 3,24,40-42$ although the actual CFR may differ significantly as the screening and identification of positive cases differs greatly from country to country. ${ }^{43}$

\section{Mechanism of Action of Chloroquine}

Chloroquine is a 4-aminoquinoline discovered in 1934 and has predominantly been used to prevent and treat malaria. ${ }^{44}$ In addition, it has been used as an anti-inflammatory agent for the treatment of a number of diseases. ${ }^{11,45} \mathrm{CQ}$ and its derivatives act as weak bases, which preferentially accumulate within intracellular compartments (including endosomes, lysosomes, and Golgi vesicles) causing a number of downstream effects; in particular, a relative increase in the endosomal and lysosomal $\mathrm{pH},{ }^{45}$ although the mechanism of action of CQ remains under continuous study in modern molecular medicine. ${ }^{46,47}$

CQ and its derivative hydroxychloroquine (HCQ) have characteristic wide volume of distribution and both can distribute to aqueous cellular and intercellular compartments resulting in long mean residence times ( 900 hours for CQ and $\sim 1,300$ hours for HCQ). ${ }^{45}$ CQ has a halflife of around 50-days and has a high renal clearance, which is an important clinical consideration in patients with kidney failure as decreased clearance increases the bioavailability of CQ. The most common adverse effect of these antimalarial drugs are gastrointestinal effects 
including nausea, vomiting, diarrhea, and abdominal discomfort. ${ }^{48}$ An important consideration is that several studies have reported the incidence of cardiotoxic effects, including rhythm disorders (such as a prolonged QT interval) and the development of cardiomyopathy in patients with rheumatic diseases, ${ }^{49-52}$ but conclusive evidence is lacking and further pharmacovigilance is required. The most severe complication attributed to antimalarial treatment is the development of retinopathy with prolonged use as these drugs can cause retinal damage by disrupting an important step in the visual cycle mediated by lysosomal degradation. ${ }^{53}$ Retinopathy is more commonly associated with CQ than with HCQ and can result in patients developing retinal defects including circular and diametric defects.

When added extracellularly, the non-protonated portion of CQ enters the cell, where it becomes protonated and concentrated in acidic, low-pH organelles. ${ }^{25}$ By increasing the $\mathrm{pH}$ of endosomal compartments, ${ }^{54} \mathrm{CQ}$ might impair the maturation of lysosomes and autophagosomes and inhibit antigen presentation along the lysosomal pathway. ${ }^{55-57}$ Interference of lysosomal activity might have an immunomodulatory effect as it could impair antigen presentation via the lysosomal pathway. Lysosomes contain hydrolytic enzymes and work with other vesicles to digest intraand extracellular material which is an underlying mechanism for antigen processing and MHC class II presentation, indirectly promoting immune activation. ${ }^{58} \mathrm{CQ}$ and HCQ have a good safety profile and are generally considered to function as immunomodulatory rather than immunosuppressant drugs. They have not been associated with an increased risk of infectious complications $^{59}$ or cancer. ${ }^{60}$

\section{RESULTS}

Chloroquine as an Anti-Coronavirus Agent 
There is compelling evidence from early trials in China highlighting the efficacy of CQ and HCQ in the treatment of SARS-CoV-2. ${ }^{11,61,62}$ In addition, there is a long trail of studies that have investigated the efficacy of CQ and its analogues, HCQ and ferrocene-chloroquine (FQ), with various species of coronavirus (Table 1). The findings, summarized and presented here, highlight the possibility that CQ and its derivatives may be effective against the novel SARS-CoV-2, which shares a close phylogenetic ancestry with previous species of coronavirus. CQ has multiple activities, one of which is to increase the $\mathrm{pH}$ of intracellular vesicles as mentioned earlier, which interferes with the $\mathrm{pH}$-dependent steps of viral replication, including fusion and uncoating. ${ }^{63}$ It is believed that lysosomotropic agents (of which CQ is included) can effectively inhibit coronavirus as the virus requires acidification of endosomes for proper functioning. ${ }^{33,44}$ For enveloped viruses, post-translational modification of the envelope glycoproteins occurs within the endoplasmic and trans-Golgi network vesicles. This process involves proteases and glycosyl-transferases, some of which require a low $\mathrm{pH}$. CQ-induced altered ACE2 glycosylation is also believed to be the mechanism by which treatment of coronavirus infected individuals acts by stopping S-protein binding and subsequent phagocytosis ${ }^{25}$ and release into the cytoplasm where viral replication occurs. ${ }^{18}$ Besides its direct antiviral effect, CQ suppresses the production of cytokines which could mediate the inflammatory complications of viral diseases. ${ }^{44}$

\section{Severe Acute Respiratory Syndrome (SARS) Coronavirus-1/2}

Both SARS-CoV-1 and -2 were studied in various cell culture lines in vitro (see Table 1). More recently, Wang et al. and Yao et al. tested the efficacy of CQ and HCQ in Vero cells derived from the kidney of an African green monkey. Wang et al. conducted time-of-addition assays studying the efficacy of a number of potential compounds, including CQ and the broad-spectrum antiviral nucleotide analog, Remdesivir. ${ }^{61}$ The authors demonstrated that CQ functioned at both 
pre- and post-entry stages of infection, demonstrating CQs antiviral activity in vitro. Yao et al. studied the efficacy of CQ and HCQ in Vero 6 cells. The authors additionally built a physiologically-based pharmacokinetic (PBPK) model to predict drug concentrations in human tissues. These models have been developed to predict the exposure, response, and time course of a drug for different dosage regimens in a target population. ${ }^{64}$ The study authors found both CQ and HCQ to have antiviral activity in vitro and decreased viral replication in a concentrationdependent manner. ${ }^{62}$

In vitro studies have also been conducted on SARS-CoV-1, which has many commonalities, and has a close phylogenetic relationship with, the novel SARS-CoV-2 belonging to the same Subgroup B lineage of betacoronaviruses. ${ }^{19}$ The efficacy of CQ against SARS-CoV-1 was assessed by both Vincent et al. and Keyaerts et al. Vincent et al. infected Vero E6 cells and treated them with both $\mathrm{CQ}$ and $\mathrm{NH}_{4} \mathrm{Cl}$, another weak base known to alter intracellular $\mathrm{pH} .{ }^{25}$ The study authors found that with pre-treatment, there was a concentration-dependent decrease in virally infected cells, with the complete elimination of infection in vitro at higher concentrations. These findings were reproduced for post-infection treatment experiments, although higher concentrations of CQ were required to inhibit the spread of infection. Interestingly, the authors also studied the effect of CQ on ACE2 receptors and viral S-protein production. Although they discovered that the surface expression of ACE2 or the level of processed S-protein did not change with treatment, they did find a decrease in the terminal glycosylation of ACE2, which may serve to render the ACE2-SARS-CoV-1 interaction less efficient. Keyaerts et al. had similar results in their earlier study. ${ }^{65}$ Biot et al. prepared new CQ and HCQ derivates, ferroquine (FQ) and hydroxyferroquine (HFQ), which retained antimalarial activity against P. falciparum. ${ }^{66}$ The authors subsequently tested the efficacy of these new compounds against SARS-CoV-1 and 
feline coronavirus and discovered these new compounds were able to exhibited inhibition of SARS-CoV-1 replication with high selectivity. It is worth noting that HCQ was ineffective against both feline coronavirus and SARS-CoV-1. de Wilde et al. likewise screened a large library of FDA approved drugs against several coronavirus species including SARS-CoV-1, as well as MERS-CoV and Human-CoV-229E in vitro. Of the screened compounds, CQ was found among several other candidates to effectively inhibit the in vitro growth of SARS-CoV-1 with no cytotoxicity.

Middle-East Respiratory Syndrome (MERS) Coronavirus

MERS-CoV is also classified under the same betacoronavirus genus as SARS-CoV-1/2, but belongs to Subgroup C lineage ${ }^{67}$ MERS coronavirus infection occurs via a similar mechanistic pathway as SARS-CoV-1/2, with the exception that it enters the cell via the dipeptidyl peptidase 4 (DPP4) receptor instead of ACE2. ${ }^{68}$ In vitro studies of CQ efficacy for MERS-CoV infection were conducted with mixed results (see Table 1). Cong et al. tested the efficacy of several candidate compounds (including CQ) in human monocyte-derived macrophages (MDMs) and immature monocyte-derived dendritic cells (MDDCs). ${ }^{69}$ Study authors revealed that CQ did not show any detectable antiviral activity in MDMs or MDDCs, although little or no cytotoxicity was reported. However, de Wilde et al. mentioned before, additionally found CQ to be an effective compound in inhibiting MERS-CoV replication in vitro among other coronaviruses. ${ }^{70}$

Other Species of Coronavirus (MHV4, Human CoV-OC43, Human CoV-229E, PHEV, FIPV)

Other species of coronavirus were studied in vitro and in vivo and the efficacy of CQ treatment were verified (see Table 1). CQ treatment was studied with two species of coronaviruses often 
responsible for the common cold during the winter and early spring, Human CoV-OC43 and Human Cov-229E. ${ }^{71}$ de Wilde et al. found CQ to act as a broad-spectrum antiviral against several coronavirus species, including $\mathrm{HCoV}-229 \mathrm{E}$, a coronavirus belonging to the alphacoronavirus genus. ${ }^{70}$ Kono et al. additionally tested the efficacy of CQ to elucidate its mechanism of action against $\mathrm{HCoV}-229 \mathrm{E}$ and discovered that the drug had a neutralizing effect on intracellular signaling proteins needed for viral replication, but had no effect on the virus prior to internalization. ${ }^{72} \mathrm{CQ}$ efficacy was also tested against the Human CoV-OC43 species, another coronavirus belonging to Subgroup A lineage of betacoronaviruses. Interestingly, Keyaerts et al. and Niu et al. studied the efficacy of CQ treatment in vivo in mouse models. For their mouse study, Keyaerts et al. passed on CQ from maternal mice either transplacentally or via maternal milk to newborn pups. ${ }^{73}$ The authors noted a $100 \%$ survival rate for newborn mice who were inoculated with $\mathrm{HCoV}-\mathrm{OC} 43$ but whose mothers were pre-treated with high dose CQ injections prepartum, with the survival rate dropping off in a dose-dependent manner. The overall survival rate of newborn mice treated with CQ via maternal milk was found to be $69 \%$ at the highest dose of CQ given, with a decreasing survival rate with lower doses. In vitro experiments were also conducted by Keyaerts in human cell lines with varying concentrations of CQ as well time-ofaddition assays. The study determined that CQ inhibits the in vitro replication of HCoV-OC43 with high selectivity, however, time-of-addition assays showed CQ is required at the moment of infection, with a loss of antiviral activity when CQ is added at later time points. Niu et al. confirmed that prophylactic CQ treatment acted to prevent virus replication in mice challenged with HCoV-OC43. ${ }^{74}$

CQ efficacy, along with its derivatives, were tested in multiple other species of coronavirus in various models. Biot et al. found that $\mathrm{CQ}$ and its derivative compounds, FQ and HFQ, were able 
to inhibit replication of feline coronavirus in vitro with high selectivity. ${ }^{66}$ However, HCQ was surprisingly ineffective in controlling both SARS-CoV-1 and feline coronavirus replication. Ding et al. explored the mechanism of autophagy induction in mouse neural cells inoculated with Porcine hemagglutinating encephalomyelitis virus (PHEV), a betacoronavirus belonging to the Subgroup A lineage. ${ }^{28}$ They then tested various compounds and their ability to control PHEV replication, including CQ. The authors found PHEV infection leads to atypical autophagy, however, they revealed that CQ was able to suppress PHEV infection. Gallagher et al. studied the infection of a selected mouse cell line by the betacoronavirus Mouse Hepatitis Virus Type 4 (Subgroup A lineage) to elucidate the mechanism of infection..$^{22}$ The study authors found that MHV4 inoculated cells treated with endosomotropic weak bases, including CQ, in the presence of persistent infection did not stop virus entrance into cells, but CQ effectively eliminated viral RNA synthesis, replication, and the processing of viral glycoprotein S. Lastly, Takano et al. studied the efficacy of CQ in both in vitro and in vivo in the presence of Feline Infectious Peritonitis Virus (FIPV), an alphacoronavirus. ${ }^{75}$ For FIPV infected cats treated with varying schedules of CQ, viral mRNA expression was lower in the pre-treatment group, the clinical score of CQ-treated groups were better than for CQ-untreated groups, and the CQ pre-treated group additionally had the highest relative survival at $34 \cdot 3$ days post infection.

\section{CONSIDERATIONS}

Although its side-effect profile is low, CQ does have some documented adverse effects. Many patients taking CQ have reported gastrointestinal upset, headache, blurred vision, insomnia, and QT interval prolongation. ${ }^{76}$ Another well-known adverse effect is the development of retinopathy with prolonged use. ${ }^{45} \mathrm{CQ}$ and HCQ have few contraindications, however patients should avoid 
use who have underlying retinopathy or a history of hypersensitivity to this class of compounds. CQ acts as an immunomodulatory agent which promotes apoptosis in cells, a critical tool of the hosts immune system in fighting infection. High CQ use globally has been theorized to lead to the emergence of diseases which have developed anti-apoptotic mechanisms, including HIV ${ }^{77}$ CQ may not be sufficient to stop viral infection, but used in conjunction with other antivirals, it may be an effective means of treatment. ${ }^{61}$ Lastly, the mechanism of action of CQ and all of its downstream effects are not fully understood. Recent findings by Xue et al. have unearthed that CQ also acts as an ionophore that aids in the intracellular transport of the mineral Zinc. ${ }^{78}$ This is an important consideration and this mechanism should be explored further given that Zinc salts have been found to block the replication of Hepatitis E virus by inhibiting the activity of viral RNA-dependent RNA-polymerase, a molecule used by SARS-CoV-2 and other coronaviruses for viral replication. ${ }^{79}$

\section{CONCLUSIONS}

The prospect of having an effective treatment for the protection of vulnerable populations and healthcare workers as well as for the treatment of those infected is noteworthy. CQ is already widely available as an anti-malarial, well tolerated, cheap, easy to take, has a low toxicity profile, and has limited contraindications for use. There is ample evidence of the in vitro and in vivo efficacy of CQ and its derivatives in the prevention and treatment of multiple species of coronavirus, including in vitro experiments with SARS-CoV-2. ${ }^{61,62}$ There are a number of clinical trials that are currently underway to test CQ and HCQ against SARS-CoV-2 as mentioned earlier. Considering its safety has already been scrutinized and it has been widely prescribed for use as an anti-malarial, Phase III randomized double-blind placebo controlled 
studied are need to assess the efficacy of CQ as a chemoprophylactic and treatment measure for SARS-CoV-2. Preliminary findings from Wang et al. have highlighted this drug's efficacy in treating SARS-CoV-2 infected individuals, ${ }^{11}$ but the trial itself has not been completed as of this writing and trial data has not been disseminated for further scrutiny. CQ and its derivatives show early promise to treat SARS-CoV-2 and should be explored as a potential preventive and therapeutic measure to turn the tide of this rapidly growing pandemic.

\section{FUNDING}

No funding was or sponsorship was received for this study or publication of this article.

\section{ACKNOWLEDGMENTS}

All named authors meet the International Committee of Medical Journal Editors (ICMJE) criteria for authorship for this article, take responsibility for the integrity of the work as a whole, and have given their approval for this version to be published. This article is based on previously conducted studies and does not contain any studies with human participants or animals performed by any of the authors.

\section{DISCLOSURES}

John E. Kearney declares that he has no conflict of interest. 


\section{REFERENCES}

1. Branswell H. WHO declares the coronavirus outbreak a pandemic. STATnews. https://www.statnews.com/2020/03/11/who-declares-the-coronavirus-outbreak-apandemic/. Published March 11, 2020. Accessed March 11, 2020.

2. Johns Hopkins University. Coronavirus COVID-19 Global Cases by Johns Hopkins CSSE. https://www.arcgis.com/apps/opsdashboard/index.html\#/bda7594740fd40299423467b48e9 ecf6. Published March 4, 2020. Accessed March 15, 2020.

3. Wang D, Hu B, Hu C, et al. Clinical Characteristics of 138 Hospitalized Patients With 2019 Novel Coronavirus-Infected Pneumonia in Wuhan, China. JAMA. 2020. Published online February 7, 2020. DOI:10.1001/jama.2020.1585.

4. Korean Society of Infectious Diseases. Report on the Epidemiological Features of Coronavirus Disease 2019 (COVID-19) Outbreak in the Republic of Korea from January 19 to March 2, 2020. J Korean Med Sci. 2020;35(10). Published online March 9, 2020. DOI:10.3346/jkms.2020.35.e112.

5. Su A. Doctors and nurses fighting coronavirus in China die of both infection and fatigue. Los Angeles Times. https://www.latimes.com/world-nation/story/2020-02-25/doctorsfighting-coronavirus-in-china-die-of-both-infection-and-fatigue. Published February 25, 2020. Accessed March 4, 2020.

6. Varia M, Wilson S, Sarwal S, et al. Investigation of a nosocomial outbreak of severe acute respiratory syndrome (SARS) in Toronto, Canada. CMAJ. 2003;169(4):285-292.

7. Wilder-Smith A, Teleman MD, Heng BH, Earnest A, Ling AE, Leo YS. Asymptomatic SARS coronavirus infection among healthcare workers, Singapore. Emerg Infect Dis. 2005;11(7):1142-1145.

8. Al-Tawfiq JA, Auwaerter PG. Healthcare-associated infections: the hallmark of Middle East respiratory syndrome coronavirus with review of the literature. J Hosp Infect. 2019;101(1):20-29.

9. Chang D, Xu H, Rebaza A, Sharma L, Dela Cruz CS. Protecting health-care workers from subclinical coronavirus infection. Lancet Respir Med. February 2020:8(3):e13.

10. Yamey G. A coronavirus vaccine should be for everyone, not just those who can afford it. STATnews. https://www.statnews.com/2020/03/05/coronavirus-vaccine-affordable-foreveryone/. Published March 5, 2020. Accessed March 10, 2020.

11. Gao J, Tian Z, Yang X. Breakthrough: Chloroquine phosphate has shown apparent efficacy in treatment of COVID-19 associated pneumonia in clinical studies. Biosci Trends. 2020. Published online February 19, 2020. DOI:10.5582/bst.2020.01047. 
12. Colson P, Rolain J-M, Raoult D. Chloroquine for the 2019 novel coronavirus SARS-CoV2. Int J Antimicrob Agents. 2020. Published online February 15, 2020. DOI:10.1016/j.ijantimicag.2020.105923.

13. Touret F, de Lamballerie X. Of chloroquine and COVID-19. Antiviral Res. 2020. Published online March 5, 2020. DOI:10.1016/j.antiviral.2020.104762.

14. Xinhua. Antimalarial drug confirmed effective on COVID-19. http://www.xinhuanet.com/english/2020-02/17/c_138792545.htm. Published February 17, 2020. Accessed March 10, 2020.

15. National Health Committee of the People's Republic of China. Interpretation of New Coronavirus Pneumonia Diagnosis and Treatment Plan (Trial Version 6). http://www.nhc.gov.cn/yzygj/s7652m/202002/54e1ad5c2aac45c19eb541799bf637e9. Published February 19, 2020. Accessed March 7, 2020.

16. Yining D. Manufacturers ramp up deliveries of coronavirus treatment drug. Shine. https://www.shine.cn/biz/economy/2002202403/. Published February 20, 2020. Accessed March 10, 2020.

17. Sung-sun K. Physicians work out treatment guidelines for coronavirus. Korea Biomedical Review. http://www.koreabiomed.com/news/articleView.html?idxno=7428. Published February 13, 2020. Accessed March 10, 2020.

18. Burkard C, Verheije MH, Wicht O, et al. Coronavirus cell entry occurs through the endo/lysosomal pathway in a proteolysis-dependent manner. PLoS Pathog. 2014;10(11):e1004502.

19. Zhu N, Zhang D, Wang W, et al. A Novel Coronavirus from Patients with Pneumonia in China, 2019. N Engl J Med. 2020;382(8):727-733.

20. Huang C, Wang Y, Li X, et al. Clinical features of patients infected with 2019 novel coronavirus in Wuhan, China. Lancet. 2020;395(10223):497-506.

21. Chen N, Zhou M, Dong X, et al. Epidemiological and clinical characteristics of 99 cases of 2019 novel coronavirus pneumonia in Wuhan, China: a descriptive study. Lancet. 2020;395(10223):507-513.

22. Gallagher TM, Escarmis C, Buchmeier MJ. Alteration of the $\mathrm{pH}$ dependence of coronavirus-induced cell fusion: effect of mutations in the spike glycoprotein. $J$ Virol. 1991;65(4):1916-1928.

23. Blau DM, Holmes KV. Human coronavirus HCoV-229E enters susceptible cells via the endocytic pathway. Adv Exp Med Biol. 2001;494:193-198.

24. Cascella M, Rajnik M, Cuomo A, Dulebohn SC, Di Napoli R. Features, Evaluation and Treatment Coronavirus (COVID-19). StatPearls [Internet]. March 2020. https://www.ncbi.nlm.nih.gov/books/NBK554776/. Accessed March 11, 2020. 
25. Vincent MJ, Bergeron E, Benjannet $\mathrm{S}$, et al. Chloroquine is a potent inhibitor of SARS coronavirus infection and spread. Virol J. 2005;2:69-69.

26. Hamming I. Novel insights in the pathogenesis of renal interstitial damage during ACE inhibition. Kidney International. 2006;70(7):1377-1378.

27. Sun P, Lu X, Xu C, Sun W, Pan B. Understanding of COVID-19 based on current evidence. J Med Virol. 2020. Published online February 25, 2020. DOI:10.1002/jmv.25722.

28. Ding N, Zhao K, Lan Y, et al. Induction of Atypical Autophagy by Porcine Hemagglutinating Encephalomyelitis Virus Contributes to Viral Replication. Front Cell Infect Microbiol. 2017;7:56.

29. Turk V, Stoka V, Vasiljeva O, et al. Cysteine cathepsins: from structure, function and regulation to new frontiers. Biochim Biophys Acta. 2012;1824(1):68-88.

30. Groneberg DA, Hilgenfeld R, Zabel P. Molecular mechanisms of severe acute respiratory syndrome (SARS). Respir Res. 2005;6(1):8-8.

31. Subissi L, Posthuma CC, Collet A, et al. One severe acute respiratory syndrome coronavirus protein complex integrates processive RNA polymerase and exonuclease activities. Proc Natl Acad Sci USA. 2014;111(37):E3900.

32. Dominguez SR, Travanty EA, Qian Z, Mason RJ. Human coronavirus HKU1 infection of primary human type II alveolar epithelial cells: cytopathic effects and innate immune response. PLoS One. 2013;8(7):e70129-e70129.

33. Simmons G, Reeves JD, Rennekamp AJ, Amberg SM, Piefer AJ, Bates P. Characterization of severe acute respiratory syndrome-associated coronavirus (SARS-CoV) spike glycoprotein-mediated viral entry. Proc Natl Acad Sci U S A. 2004;101(12):4240-4245.

34. Heald-Sargent T, Gallagher T. Ready, set, fuse! The coronavirus spike protein and acquisition of fusion competence. Viruses. 2012;4(4):557-580.

35. Follis KE, York J, Nunberg JH. Furin cleavage of the SARS coronavirus spike glycoprotein enhances cell-cell fusion but does not affect virion entry. Virology. 2006;350(2):358-369.

36. de Haan CAM, Stadler K, Godeke G-J, Bosch BJ, Rottier PJM. Cleavage inhibition of the murine coronavirus spike protein by a furin-like enzyme affects cell-cell but not virus-cell fusion. J Virol. 2004;78(11):6048-6054.

37. Zhao W, Zhong Z, Xie X, Yu Q, Liu J. Relation Between Chest CT Findings and Clinical Conditions of Coronavirus Disease (COVID-19) Pneumonia: A Multicenter Study. AJR Am J Roentgenol. March 2020:1-6. Published online March 3, 2020. DOI:10.2214/AJR.20.22976.

38. Zumla A, Hui DS, Azhar EI, Memish ZA, Maeurer M. Reducing mortality from 2019nCoV: host-directed therapies should be an option. Lancet. 2020;395(10224):e35-e36. 
39. Chen L, Liu HG, Liu W, et al. Analysis of clinical features of 29 patients with 2019 novel coronavirus pneumonia. Zhonghua Jie He He Hu Xi Za Zhi. 2020;43(0):E005-E005. Published online February 6, 2020. DOI:10.3760/cma.j.issn.1001-0939.2020.0005.

40. Guan W, Ni Z, Hu Y, et al. Clinical Characteristics of Coronavirus Disease 2019 in China. N Engl J Med. February 2020.

41. Wu Y-C, Chen C-S, Chan Y-J. The outbreak of COVID-19: An overview. J Chin Med Assoc. 2020;83(3):217-220.

42. Han Q, Lin Q, Jin S, You L. Recent insights into 2019-nCoV: a brief but comprehensive review. J Infect. 2020. Published online February 25, 2020.

DOI:10.1016/j.jinf.2020.02.010.

43. Worldometer. Coronavirus Testing: Criteria and Numbers by Country. worldometer.info. https://www.worldometers.info/coronavirus/covid-19-testing/. Published March 9, 2020. Accessed March 11, 2020.

44. Savarino A, Boelaert JR, Cassone A, Majori G, Cauda R. Effects of chloroquine on viral infections: an old drug against today's diseases? Lancet Infect Dis. 2003;3(11):722-727.

45. Schrezenmeier E, Dörner T. Mechanisms of action of hydroxychloroquine and chloroquine: implications for rheumatology. Nat Rev Rheumatol. 2020;16(3):155-166.

46. Flannery EL, Chatterjee AK, Winzeler EA. Antimalarial drug discovery - approaches and progress towards new medicines. Nat Rev Microbiol. 2013;11(12):849-862.

47. Ridley RG. Medical need, scientific opportunity and the drive for antimalarial drugs. Nature. 2002;415(6872):686-693.

48. Srinivasa A, Tosounidou S, Gordon C. Increased Incidence of Gastrointestinal Side Effects in Patients Taking Hydroxychloroquine: A Brand-related Issue? J Rheumatol. 2017;44(3):398.

49. Dogar MU, Shah NN, Ishtiaq S, et al. Hydroxychloroquine-induced restrictive cardiomyopathy: a case report. Postgrad Med J. 2018;94(1109):185-186.

50. Chang ICY, Bois JP, Bois MC, Maleszewski JJ, Johnson GB, Grogan M. Hydroxychloroquine-Mediated Cardiotoxicity With a False-Positive (99m)TechnetiumLabeled Pyrophosphate Scan for Transthyretin-Related Cardiac Amyloidosis. Circ Cardiovasc Imaging. 2018;11(1):e007059.

51. Chatre C, Roubille F, Vernhet H, Jorgensen C, Pers Y-M. Cardiac Complications Attributed to Chloroquine and Hydroxychloroquine: A Systematic Review of the Literature. Drug Saf. 2018;41(10):919-931.

52. Costedoat-Chalumeau N, Hulot J-S, Amoura Z, et al. Heart conduction disorders related to antimalarials toxicity: an analysis of electrocardiograms in 85 patients treated with 
hydroxychloroquine for connective tissue diseases. Rheumatology (Oxford). 2007;46(5):808-810.

53. Jorge A, Ung C, Young LH, Melles RB, Choi HK. Hydroxychloroquine retinopathy implications of research advances for rheumatology care. Nat Rev Rheumatol. 2018;14(12):693-703.

54. Ohkuma S, Poole B. Fluorescence probe measurement of the intralysosomal $\mathrm{pH}$ in living cells and the perturbation of $\mathrm{pH}$ by various agents. Proc Natl Acad Sci U S A. 1978;75(7):3327-3331.

55. Mauthe M, Orhon I, Rocchi C, et al. Chloroquine inhibits autophagic flux by decreasing autophagosome-lysosome fusion. Autophagy. 2018;14(8):1435-1455.

56. Frustaci A, Morgante E, Antuzzi D, Russo MA, Chimenti C. Inhibition of cardiomyocyte lysosomal activity in hydroxychloroquine cardiomyopathy. Int J Cardiol. 2012;157(1):117119.

57. Sundelin SP, Terman A. Different effects of chloroquine and hydroxychloroquine on lysosomal function in cultured retinal pigment epithelial cells. APMIS. 2002;110(6):481489.

58. Lotteau V, Teyton L, Peleraux A, et al. Intracellular transport of class II MHC molecules directed by invariant chain. Nature. 1990;348(6302):600-605.

59. Ruiz-Irastorza G, Olivares N, Ruiz-Arruza I, Martinez-Berriotxoa A, Egurbide M-V, Aguirre C. Predictors of major infections in systemic lupus erythematosus. Arthritis Res Ther. 2009;11(4):R109.

60. Lazarus MN, Robinson D, Mak V, Moller H, Isenberg DA. Incidence of cancer in a cohort of patients with primary Sjogren's syndrome. Rheumatology (Oxford). 2006;45(8):10121015.

61. Wang M, Cao R, Zhang L, et al. Remdesivir and chloroquine effectively inhibit the recently emerged novel coronavirus (2019-nCoV) in vitro. Cell Res. 2020;30(3):269-271.

62. Yao X, Ye F, Zhang M, et al. In Vitro Antiviral Activity and Projection of Optimized Dosing Design of Hydroxychloroquine for the Treatment of Severe Acute Respiratory Syndrome Coronavirus 2 (SARS-CoV-2). Clin Infect Dis. 2020. Published online March 9, 2020. DOI:10.1093/cid/ciaa237.

63. Rolain J-M, Colson P, Raoult D. Recycling of chloroquine and its hydroxyl analogue to face bacterial, fungal and viral infections in the 21 st century. Int J Antimicrob Agents. 2007;30(4):297-308.

64. Jones H, Rowland-Yeo K. Basic concepts in physiologically based pharmacokinetic modeling in drug discovery and development. CPT Pharmacometrics Syst Pharmacol. 2013;2(8):e63-e63. 
65. Keyaerts E, Vijgen L, Maes P, Neyts J, Van Ranst M. In vitro inhibition of severe acute respiratory syndrome coronavirus by chloroquine. Biochem Biophys Res Commun. 2004;323(1):264-268.

66. Biot C, Daher W, Chavain N, et al. Design and synthesis of hydroxyferroquine derivatives with antimalarial and antiviral activities. J Med Chem. 2006;49(9):2845-2849.

67. Chan JF-W, Kok K-H, Zhu Z, et al. Genomic characterization of the 2019 novel humanpathogenic coronavirus isolated from a patient with atypical pneumonia after visiting Wuhan. Emerging Microbes \& Infections. 2020;9(1):221-236.

68. Raj VS, Mou H, Smits SL, et al. Dipeptidyl peptidase 4 is a functional receptor for the emerging human coronavirus-EMC. Nature. 2013;495(7440):251-254.

69. Cong Y, Hart BJ, Gross R, et al. MERS-CoV pathogenesis and antiviral efficacy of licensed drugs in human monocyte-derived antigen-presenting cells. PLoS One. 2018;13(3):e0194868.

70. de Wilde AH, Jochmans D, Posthuma CC, et al. Screening of an FDA-approved compound library identifies four small-molecule inhibitors of Middle East respiratory syndrome coronavirus replication in cell culture. Antimicrob Agents Chemother. 2014;58(8):48754884.

71. Larson HE, Reed SE, Tyrrell DA. Isolation of rhinoviruses and coronaviruses from 38 colds in adults. $J$ Med Virol. 1980;5(3):221-229.

72. Kono M, Tatsumi K, Imai AM, Saito K, Kuriyama T, Shirasawa H. Inhibition of human coronavirus 229E infection in human epithelial lung cells (L132) by chloroquine: involvement of p38 MAPK and ERK. Antiviral Res. 2008;77(2):150-152.

73. Keyaerts E, Li S, Vijgen L, et al. Antiviral Activity of Chloroquine against Human Coronavirus OC43 Infection in Newborn Mice. Antimicrob Agents Chemother. 2009;53(8):3416.

74. Niu J, Shen L, Huang B, et al. Non-invasive bioluminescence imaging of HCoV-OC43 infection and therapy in the central nervous system of live mice. Antiviral Res. 2020;173:104646-104646.

75. Takano T, Katoh Y, Doki T, Hohdatsu T. Effect of chloroquine on feline infectious peritonitis virus infection in vitro and in vivo. Antiviral Res. 2013;99(2):100-107.

76. Hill SR, Sharma GK. Antimalarial Medications. StatPearls [Internet]. https://www.ncbi.nlm.nih.gov/books/NBK470158/. Published December 6, 2019. Accessed March 11, 2020.

77. Parris GE. Hypothesis links emergence of chloroquine-resistant malaria and other intracellular pathogens and suggests a new strategy for treatment of diseases caused by intracellular parasites. Med Hypotheses. 2004;62(3):354-357. 
78. Xue J, Moyer A, Peng B, Wu J, Hannafon BN, Ding W-Q. Chloroquine Is a Zinc Ionophore. PLOS ONE. 2014;9(10):e109180.

79. Kaushik N, Subramani C, Anang S, et al. Zinc Salts Block Hepatitis E Virus Replication by Inhibiting the Activity of Viral RNA-Dependent RNA Polymerase. J Virol. 2017;91(21):e00754-17. 
Table 1: Studies showing the in vitro/in vivo efficacy of CQ (and its derivatives) against coronavirus species

\begin{tabular}{|c|c|c|c|c|c|c|}
\hline Author & Year & $\begin{array}{l}\text { CQ or CQ } \\
\text { Analog }\end{array}$ & $\begin{array}{l}\text { Coronavirus } \\
\text { Species }\end{array}$ & Genus & Lineage & Study Design \\
\hline Wang et al. & 2020 & $\begin{array}{l}\mathrm{CQ} \text { (w/ } \\
\text { Remdesivir) }\end{array}$ & SARS-CoV-2 & Betacoronavirus & Subgroup B & $\begin{array}{l}\text { Standard assays were carried out to measure the } \\
\text { effects of several compounds, including CQ and the } \\
\text { anti-HIV-1 drug Remdesivir. Vero E6 cells* were } \\
\text { used to assess cytotoxicity and infection in the } \\
\text { presence of varying concentrations of test drugs. }\end{array}$ \\
\hline Yao et al. & 2020 & CQ, HCQ & SARS-CoV-2 & Betacoronavirus & Subgroup B & $\begin{array}{l}\text { Pharmacological activity of CQ and HCQ were } \\
\text { tested using SARS-CoV-2 infected Vero Cells.* } \\
\text { The authors also built a physiologically-based } \\
\text { pharmacokinetic (PBPK) model to predict drug } \\
\text { concentrations in human tissues. }\end{array}$ \\
\hline Vincent et al. & 2005 & CQ & SARS-CoV-1 & Betacoronavirus & Subgroup B & $\begin{array}{l}\text { Vero E6 cells* were infected and treated with CQ } \\
\text { and ammonium chloride pre- and post-infection. } \\
\text { In addition, CQ activity against SARS-CoV-1 was } \\
\text { studied by characterizing the drug's effect on cell } \\
\text { surface expression of ACE2, structural changes to } \\
\text { the ACE2 receptor, and the biosynthesis and } \\
\text { processing of SARS-CoV-1 spike protein. }\end{array}$ \\
\hline
\end{tabular}

Results

Time-of-addition assays demonstrated that CQ functioned at both entry and at post-entry stages of SARS-CoV-2 infection in Vero E6 cells.

Results showed that both drugs had antiviral activity in vitro and were found to decrease viral replication in a

concentration-dependent manner. HCQ exhibited a superior in vitro antiviral effect.

Authors found a concentration-dependent decrease in virus antigen-positive cells, with the complete abolishment of SARS-CoV-1 infection at higher concentrations in pre-

treatment experiments. The results were replicated with postinfection treatment, with higher concentrations of CQ almost completely inhibiting the spread of infection to adjacent cells in culture.

The authors found that CQ did not alter the surface expression of ACE2 receptors, but found that there was a decrease in the terminal glycosylation of ACE2, which is thought to render the ACE2-SARS-CoV-1 interaction less efficient and inhibit viral entry. Last, the authors found that, except for higher concentrations, there was no decrease in biosynthesis and in levels of processed virus spike glycoprotein.

FQ was found to be effective inhibitors of SARS-CoV-1 replication in Vero cells. FQ and HFQ compounds were also Auhors prepared a new class of CQ deriva (HF/HFQ) which closely mimic the activity of antimalarial drugs. HFQ was tested to see if it could found to inhibit feline coronavirus in vitro. These compounds retain antimalarial activity against $\mathrm{P}$. falciparum and also exhibited a high selectivity index as well. CQ was used a different set of viruses including SARS-CoV-1 as a control and found to inhibit both SARS-CoV-1 and feline and feline coronavirus.

Keyaerts et al. 2004 CQ $\quad$ SARS-CoV-1 Betacoronavirus $\quad$ Subgroup B

Authors tested the efficacy and cytotoxicity of CQ against SARS-CoV-1 in Vero E6 cells.* Authors also conducted time-of-addition assays to test the efficacy of CQ at time of infection as well as 8 hours post-infection.

$\begin{array}{lll}\text { de Wilde et al. } 2014 \text { CQ } & \begin{array}{l}\text { SARS-CoV-1, } \\ \text { MERS-CoV, }\end{array} & \begin{array}{l}\text { Betacoronavirus } \\ \text { (SARS-CoV-1, }\end{array}\end{array}$

Human CoV-229E MERS-CoV),

Alphaconavirus Subgroup $\mathrm{C}$

$\begin{array}{ll}\text { Subgroup B } & \text { Screening for FDA-approved compounds with anti- } \\ \text { (SARS-CoV-1) } & \text { MERS-CoV activity. A primary library screen was }\end{array}$ performed using a set of 348 FDA-approved drugs that were evaluated for their ability to inhibit the (H-CoV-229E) replication of MERS-CoV in Vero cells. coronavirus, while HCQ did not.

In the virus yield assay, no significant infection was observed in vitro 1 - and 3-days post-infection. It was found that a higher concentration of CQ was needed 3-days post-infection to inhibit viral replication.

Authors found that CQ inhibits MERS-CoV and Human$\mathrm{CoV}-229 \mathrm{E}$ replication in vitro at low-micromolar

concentrations in the absence of cytotoxicity of uninfected control cells. In addition, these molecules appear to be broadspectrum coronavirus inhibitors, as they blocked the replication of human coronavirus $229 \mathrm{E}$ and SARS-CoV-1 with comparable efficacy. 
Table 1: Studies showing the in vitro/in vivo efficacy of CQ (and its derivatives) against coronavirus species

\begin{tabular}{|c|c|c|c|c|c|c|}
\hline Author & Year & $\begin{array}{l}\text { CQ or CQ } \\
\text { Analog }\end{array}$ & $\begin{array}{l}\text { Coronavirus } \\
\text { Species } \\
\end{array}$ & Genus & Lineage & Study Design \\
\hline Cong et al. & 2018 & CQ & MERS-CoV & Betacoronavirus & Subgroup C & $\begin{array}{l}\text { Authors tested the efficacy of several candidate } \\
\text { MERS-antivirals (including CQ) in human } \\
\text { monocyte-derived macrophages (MDMs) and } \\
\text { immature monocyte-derived dendritic cells } \\
\text { (MDDCs). Cytotoxicity assays were performed in } \\
\text { parallel to measure drug toxicity. Antiviral activity } \\
\text { was evaluated by means of a 50\% tissue culture } \\
\text { infectious dose. }\end{array}$ \\
\hline
\end{tabular}

Keyaerts et al. 2009 CQ Human CoV-OC43 Betacoronavirus Subgroup A

Niu et

2008

CQ

Human CoV-OC43 Betacoronavirus

Subgroup A

Kono et al

Ding et al. 2017 CQ PHEV (Porcine

hemagglutinating

encephalomyelitis

virus)

Gallagher et al. 1991

CQ
Subgroup A

\section{Betacoronavirus Subgroup A}

\section{MHV4}

(Coronavirus

Betacoronavirus

Mouse Hepatitis

Mouse Hepatitis
Virus Type 4 ) $* *$ infectious dose.

Authors tested various concentrations of CQ against CQ inhibits the in vitro replication of HCoV-OC43 with a the human coronavirus-OC43 in a human cell line (HRT-18). Time-of-addition assays were also conducted where CQ was added at the time of infection or at different time points thereafter.

Mouse infection studies were also conducted where one population of female mice were treated with $\mathrm{CQ}$ which was passed onto newborn pups transplacentally who were subsequently inoculated with virus (HCoV-OC43). Another population of newborn pups were exposed to $\mathrm{CQ}$ via maternal milk of CQ injected maternal mice. The pups were then inoculated with $\mathrm{HCoV}-\mathrm{OC} 43$.

Authors tested the efficacy of CQ treatment in vivo in a mouse model. Mice were treated prophylactically with CQ and then infected intranasally with HCoV-OC43.

Authors studied the correlation between CQ and the activation of intracellular signaling protein production in $\mathrm{HCoV}-229 \mathrm{E}$ infected human fetal lung cells, the effect of $C Q$ on viral replication, and the effect of $\mathrm{CQ}$ on the internalization of virus.

Authors explored the mechanism of autophagy induction by PHEV infection in Neuro-2a cells, a the role of autophagy in PHEV replication. The authors also investigated the change in viral replication by various compounds including $\mathrm{CQ}$. Selected mouse cells were used for propagation of wild-type MHV4 in persistently infected cells. Virus-specific RNA synthesis was monitored. Variants of the mouse line that were persistently infected with MHV4 were selected for by the formation of extensive syncytium.
Results

CQ did not show any detectable antiviral activity in MDMs or MDDCs, although little to no cytotoxicity was associated with the compound.

high selectivity.

For time-of-addition assays, measurements of viral load show that $\mathrm{CQ}$ is required at the moment of infection to block

$\mathrm{HCoV}-\mathrm{OC} 43$ replication. At later time points, a loss of the antiviral activity of $\mathrm{CQ}$ was noted.

For newborn mice studies, authors found that all pups untreated died within 6 days post-HCoV-OC43 challenge. A $100 \%$ survival rate was found in litters of the mother mice that were treated with high concentrations of CQ prepartum, with decreasing survival rates in a dose-dependent manner. The survival rate of newborn mice that received CQ via maternal milk was $69 \%$.

Mice treated with CQ exhibited no detectable signal from the virus in bioluminescent assays. Western blot analysis of infected mice confirmed the efficacy of CQ in preventing virus replication

CQ treatment was demonstrated to have a neutralizing effect on intracellular signaling proteins needed for viral replication. $\mathrm{CQ}$ has no influence on the process prior to the internalization of $\mathrm{HCoV}-229 \mathrm{E}$.

PHEV infection was found to induce atypical autophagy which is involved in viral replication. After infection with PHEV, treatment with CQ suppressed PHEV infection.

Authors found that the weak base CQ does not inhibit viral fusion and endocytosis but it did inhibit internal processing of the virus needed for cytosolic release and replication as well as processing of glycoprotein $\mathrm{S}$ (spike) for further infection. 
Table 1: Studies showing the in vitro/in vivo efficacy of CQ (and its derivatives) against coronavirus species

\begin{tabular}{|c|c|c|c|c|c|c|c|}
\hline Author & Year & $\begin{array}{l}\text { CQ or CQ } \\
\text { Analog }\end{array}$ & $\begin{array}{l}\text { Coronavirus } \\
\text { Species }\end{array}$ & Genus & Lineage & Study Design & Results \\
\hline \multirow[t]{2}{*}{ Takano et al. } & 2013 & CQ & $\begin{array}{l}\text { FIPV (Feline } \\
\text { Infectious } \\
\text { Peritonitis Virus) }\end{array}$ & Alphacoronavirus & & $\begin{array}{l}\text { Authors investigated if CQ inhibited FIPV } \\
\text { replication in a feline fetal cell line. }\end{array}$ & $\begin{array}{l}\text { FIPV replication was inhibited in a CQ dose-dependent } \\
\text { manner in both pre- and post-treatment groups in infected } \\
\text { feline cells. }\end{array}$ \\
\hline & & & & & & $\begin{array}{l}\text { CQ efficacy was also studied in vivo in FIPV } \\
\text { infected cats in a time-of-addition assay. }\end{array}$ & $\begin{array}{l}\text { For FIPV infected cats treated with varying schedules of CQ, } \\
\text { viral mRNA expression was lower in the pre-treatment group. } \\
\text { The clinical score of CQ-treated groups were better than for } \\
\text { CQ-untreated groups. The CQ pre-treated group additionally } \\
\text { had the highest relative survival. }\end{array}$ \\
\hline
\end{tabular}

* Isolated from the kidney epithelial cells of African Green Monkey.

** Feline coronavirus in Crandell-Reese feline kidney (CRFK) cells.

*** This species of coronavirus was selected for as it is dependent on endosomal $\mathrm{pH}$ for phagocytosis. 